\title{
CORRESPONDENCE/
}

\section{Orphan Drug Debate}

To the editor:

By advocating changes in the highly successful Orphan Drug Act ("Poor Little Rich Drugs?" Bio/Technology 10:464, April, 1992), Senator Howard M. Metzenbaum would impose unacceptable risks on the 10,000 to 20,000 Americans who suffer from the 5,000 rare diseases for which no effective treatments have yet been developed.

At a recent hearing, Food and Drug Administration Commissioner David Kessler warned legislators: "We must not tinker with this very successful act. I don't think we know enough about these market forces to make certain any changes we make will not hurt."

There is already strong evidence that they will hurt. More than one-third of the companies responding to the survey by the Pharmaceutical Manufacturers Association in mid1990 said that uncertainty about the future of the Orphan Drug Act was adversely affecting their decisions about orphan-drug research. And more than 50 percent stated that a sales cap would be sufficient reason not to pursue orphandrug research. Further evidence of this chilling effect may be found in the fact that the industry-sponsored Commission on Drugs for Rare Diseases has, so far, failed to find sponsors for five potential rare disease medicines.

Pharmaceutical R\&D is already expensive and risky. A sales cap of $\$ 200$ million after which a manufacturer would lose market exclusivity - as proposed by Senator Metzenbaumwould increase the odds against recovering R\&D costs. For example, suppose a company developed a drug for a disease with a patient population of about 150,000 , such as multiple sclerosis. If the medicine costs $\$ 75$ per month, the sales cap would be reached in about a year and a half. And a medicine for a disease affecting 30,000-such as cystic fibrosis or amyotrophic lateral sclerosis (Lou Gehrig's disease)-that costs $\$ 200$ a month would reach the cap in less than three years. And these hypothetical treatment costs are lower than the current costs of maintaining, rather than treating, people with these diseases.

The changes in the law contemplated by Senator Metzenbaum would seriously weaken the incentives to undertake orphan drug research. That would dim the hopes of millions of Americans who suffer from rare diseases.

Gerald J. Mossinghoff President

Pharmaceutical Manufacturers Association Washington, $D C$

To the editor:

There is very little disagreement that the Orphan Drug Act has been a tremendous success. More drugs and treatments have been developed for orphan diseases in the last five years than ever before. It should be no surprise that the United States leads the world in the creation of safe and effective orphan drugs. In fact, orphan drug development outside this country is almost non-existent.

The fundamental incentive provided in the Orphan Drug Act is a seven-year period of exclusivity for the first company that receives FDA approval for a specific product to treat a specific orphan discase. It

\section{Correction}

Table 1 in "International Strategic Alliances"by Richard A. Schwartz and Mark D. Dibner ( Bio/Technology10:528-533) contained an error. The corrected table appears below.

Table 1. Direction of technology flow.

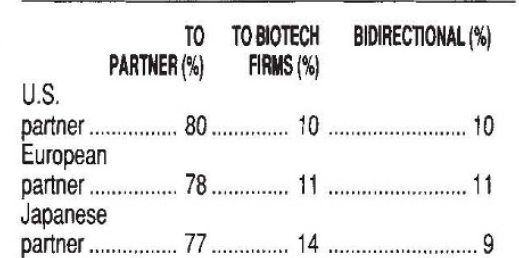

does not cxclude companies from developing other products or improved products for the same orphan disease or the same product for another disease. The exclusivity provision only stops companies from simply copying the pioneering work done by the first company. It stops the creation of instantaneous generics.

It is this provision that allows companies to justify starting the 10-year, highly risky research cycle to develop a drug, and to raise the $\$ 50$ to $\$ 200$ million required to finance the development and set up manufacturing of the product. The promise of a limited period of exclusivity actually encourages more companies to attempt to produce therapeutic solutionsfor an orphan disease than otherwise would. Changing or capping this exclusivity provision would immediately impact $\mathrm{R} \& \mathrm{D}$ investment.

Those in favor of changing the Orphan Drug Act argue that it was never intended to create highly successful drugs. This is a shortsighted view. Take the case of cystic fibrosis. This is the most common, fatal, Caucasian genetic disorder in the country. Thirty thousand children and young adults have the disease and most will die before age 30 . The direct medical cost of treating these patients approaches $\$ 1$ billion per year.

Clearly a product that controls this devastating problem would provide a tremendous payback to society. Such a product would be an Orphan Drug, and from projections of its sales would no doubt qualify for the "blockbuster" characterization. The special, almost subtle incentive of the Orphan Drug Act has helped create a tremendous encrgy and determination to develop an effective treatment for cystic fibrosis. Patents might well turn out to be more important in this case than the Orphan Drug Act. But as long as patents have not been issued, it is difficult to rely on them.

Those in favor of change also argue that the Act is responsible for high drug prices. This argument cannot be substantiated. The drug mentioned often in this regard is Ceredase, for the treatment of Gaucher's disease. While this product, priced on the basis of cost and therapy, is expensive, the drug provides a return which is significantly lower than the industry standard. Fortunately, in the case of Ceredase, annual treatment costs drop dramatically, as much as 75 to 80 percent after the initial six months to one year period of intensive treatment. The treatment cost of hemophilia (Factor VIII) is higher than the maintenance treatment cost of Gaucher's disease despite the presence of five competitive suppliers.

Changing the Orphan Drug Act as is proposed is unlikely to affect the cost of treating orphan disease, but is surely going to affect the future availability of new treatments.

The real cost to society of not treating devastating diseases such as cystic fibrosis is extremely high and unacceptable if treatments can be created. The cost of health care in this country is high and is growing out of control, and we are starting to focus on the productivity of health care investments. The productivity of the Orphan Drug Act is an encouraging example.

Henri A. Termeer

Chairman, President, and CEO Genzyme Corporation Cambridge, $M A$ 